\title{
Immune parameters to consider when choosing T-cell receptors for therapy
}

\author{
Scott R. Burrows ${ }^{1,2}$ and John J. Miles ${ }^{1,2,3} *$ \\ 1 Human Immunity Laboratory and Cellular Immunology Laboratory, Queensland Institute of Medical Research, Brisbane, QLD, Australia \\ 2 School of Medicine, The University of Queensland, Brisbane, OLD, Australia \\ ${ }^{3}$ Institute of Infection and Immunity, Cardiff University School of Medicine, Cardiff, Wales, UK
}

Edited by:

Bruno Laugel, Cardiff University

School of Medicine, UK

\section{Reviewed by:}

Liisa Kaarina Selin, University of

Massachusetts Medical School, USA

Mirjam Heemskerk, Leiden University

Medical Center, Netherlands

\section{*Correspondence:}

John J. Miles, Human Immunity

Laboratory, Queensland Institute of

Medical Research, 300 Herston Road,

Herston, Brisbane, QLD 4006,

Australia

e-mail:john.miles@qimr.edu.au
T-cell receptor (TCR) therapy has arrived as a realistic treatment option for many human diseases. TCR gene therapy allows for the mass redirection of T-cells against a defined antigen while high affinity TCR engineering allows for the creation of a new class of soluble drugs. However, deciding which TCR blueprint to take forward for gene therapy or engineering is difficult. More than one quintillion TCR combinations can be generated by somatic recombination and we are only now beginning to appreciate that not all are functionally equal. TCRs can exhibit high or low degrees of HLA-restricted cross-reactivity and alloreact against one or a combination of HLA alleles. Identifying TCR candidates with high specificity and minimal cross-reactivity/alloreactivity footprints before engineering is obviously highly desirable. Here we will summarize what we currently know about TCR biology with regard to immunoengineering.

Keywords: T-cell epitope, T-cell receptor, T-cell engineering

\section{BACKGROUND}

The $\alpha \beta$ T-cell receptor (TCR) is one of the most variable proteins known to science (1) with the human $\mathrm{V}(\mathrm{D}) \mathrm{J}$ recombination system capable of generating hundreds of trillion of unique $\alpha \beta$ TCR molecules (2). This incredibly vast receptor reserve is our immune systems' core defense against the torrent of hypervariable microorganisms and pathogenic challenges encountered over the course of life. During thymopoiesis, the TCR recombination machinery uses "cut-and-paste" transposition to incise and rearrange 174 variable (TRAV and TRBV), diversity (TRBD), joining (TRAJ and TRBJ), and constant (TRAC and TRBC) TCR gene segments on chromosomes 7 (TRB loci) and 14 (TRA loci) into around sevenand-a-half million distinctive gene combinations (2). This chromosomal recombination process generates only around $10 \%$ of total TCR diversity with the remaining $90 \%$ of diversity generated through further exonuclease activity and the addition of random, non-template-dependent nucleotides (N-nucleotides) across the $\mathrm{V}(\mathrm{D}) \mathrm{J}$ junction by the enzyme terminal deoxynucleotidyl transferase (TdT) (3). The collective sum of this recombination event is a theoretical $10^{15}-10^{20}$ structurally unique $\alpha \beta$ TCR molecules $(1$, $4,5)$. Due to size constraints (2), the human immune system only houses an infinitely small slice of the full repertoire. In an adult human, this equates to $10^{12} \mathrm{~T}$-cells $(6,7)$ bearing around $2.5 \times 10^{6}$ unique $\alpha \beta$ TCR structures (6), with the upper bounds comprising $10^{8}-10^{11}$ unique $\alpha \beta$ TCR structures per individual $(6,7)$.

The $\alpha \beta$ TCR is a glycosylated, membrane-integral surface protein comprising one $\alpha$-chain and one $\beta$-chain (2). The two chains fold and fuse via cysteine-cysteine disulfide linkers to produce a single, functional heterodimeric receptor $(8,9)$. The outward facing and solvent-exposed edge of the heterodimer bears six highly flexible complementarity determining region (CDR) loops. The CDR1 and CDR2 loops are encoded by the germline TRAV and
TRBV genes and generally function to fix the TCR to the major histocompatibility complex (MHC) platform. Conversely, the CDR3 loops are encoded by the somatically hypervariable $\mathrm{V}(\mathrm{D}) \mathrm{J}$ junction and classically function to engage the peptide (p) cradled in the MHC groove $(8,9)$, although variations on CDR binding geometry have been noted (9).

A TCR engages its cognate pMHC as a single, composite ligand, and docks in an approximately diagonal fashion that slightly varies in pivot and tilt from complex to complex $(9,10)$. One steady constant of TCR/pMHC engagement is that the CDR $3 \alpha$ loop is positioned toward the direction of the peptide $\mathrm{N}$-terminus and the CDR3 $\beta$ loop is positioned toward the direction of the peptide $\mathrm{C}$-terminus and variation in this geometry has not been seen to date $(9,10)$, however extreme terminal focusing has been recently observed (11). The TCR/pMHC docking process can be very fluid and conformational changes to the TCR, peptide, and MHC have all been observed suggesting that both interfaces often adjust to each other to find a compatible binding solution (9). Biophysical data show that TCR binding is stratified based on function. TCRs that engage pMHC class-I (pMHC-I) targets bind strongly with a mean affinity three time stronger than TCRs that engage pMHC class-II (pMHC-II) targets (8). Likewise, TCRs are further stratified based on whether the antigen target is of self or foreign origin, with foreign-reactive TCRs binding cognate pMHC with a mean affinity 10 times stronger than TCRs that bind self pMHC (8).

In spite of the large number of TCR receptor "options" available in the naive repertoire, T-cell repertoires deployed against pMHC antigens often exhibit ordered and predictable TCR gene architecture [reviewed $(2,12)]$. This phenomenon, termed TCR bias, can result in residue-identical memory clonotypes being found across multiple individuals sharing a common MHC allele. The mechanisms behind the appearance of these "public" T-cell 
responses are still being determined (2) but is thought to involve both biases in recombination during thymopoiesis (13) and some optimal, structural-based, filtering event during antigen-driven selection (14-20). For this filtering event, it appears the peptide is the determining factor during repertoire formation (21) with TCR repertoire assembly not dependent on antigen source, presenting MHC allele or immunodominance hierarchy. Once a memory T-cell repertoire is established, it appears to remain relatively consistent both in terms of clonotype stability and clonotype frequency over decades of life $(22,23)$.

Adoptive cell therapy (ACT) using antigen-specific T-cells has proven to be a remarkably effective experimental treatment option for Epstein-Barr virus malignancies (24), cytomegalovirus infection (25), and melanoma (26). Given these promising results, many groups have turned toward TCR gene transfer as a simpler, faster, and more homogeneous technique for generating ACTs. Here, antigen-specific $\alpha \beta$ TCR genes are delivered into recipient T-cells using a $\gamma$-retroviral vector, lentiviral vector, or transposon [reviewed (26)]. Another parallel approach for TCR therapy is to engineer high affinity mutants from natural $\alpha \beta$ TCR "blueprints" using yeast display (27) or phage display (28). These TCR mutants can have their binding affinities amplified logarithmically to the low $\mathrm{pM} K_{\mathrm{D}}$ range (28) while still retaining high specificity for antigen $(28,29)$. Affinity enhanced TCR can be used in two ways. First the mutants can be gene transferred into T-cells to increase antigen sensitivity and polyfunctionality (30). Second, the mutants can be used in soluble form to deliver therapeutic payloads to cells bearing the appropriate pMHC targets (31). Importantly, before considering a receptor for therapeutic ends, a number of parameters should be considered regarding the genetics and biology of the human TCR.

\section{CONSIDERATION ONE: CROSS-REACTIVITY}

The first parameter to considering when applying TCR therapy is the cross-reactivity profile of the candidate receptor. A theoretical proposal (32) predicted that the $\alpha \beta$ TCR must intrinsically encode a high degree of cross-reactivity in order to provide sufficient coverage against the huge constellation of pMHC complexes that could be encountered in nature. Through the use of combinatorial peptide libraries (CPLs), that comprise almost all possible peptides of a particular length, this theory was recently tested experimentally and proven $(33,34)$. In the context of a single MHC, a single $\alpha \beta$ TCR can recognize over one million different peptides as well or better than its cognate ligand (34). Whether this is the case for all TCRs is under active investigation. Very recent CPL data suggests that TCRs have sliding cross-reactive intensities (35) and, at least for pMHC-I-specific TCRs, an explicit preference for peptides of defined length. Thus, cross-reactivity for peptides outside a TCRs "programmed length preference" is unlikely.

Given the intrinsic cross-reactivity of TCRs, it is tempting to select for TCR that engage multiple target pMHC. Indeed, this "multiple birds with one stone" approach could dramatically boost therapeutic efficacy of a candidate TCR in vivo. However, caution is advised in this pursuit as it has recently been shown that multipMHC specific TCR can result in serious side effects (36). Here, a therapeutic TCR that recognized multiple MAGE-derived peptides resulted in neurological toxicity when administered to melanoma patients as TCR gene therapy. Off-target toxicity was thought to be due to one of the MAGE peptides being expressed in the brain. This localized expression profile was not previously known.

Another parameter to consider (on top of the large numbers of proteogenic peptides T-cells can recognize) is the issue of "transformed self." It is known that $\alpha \beta$ T-cells can engage proteogenic peptides containing post-translational modifications, such as phosphorylation (37), glycosylation (38), citrullination (39), and dimerization (40). Whether a given $\alpha \beta$ TCR also crossrecognizes large numbers of modified peptides is yet to be determined. In addition to classical pMHC-I and pMHC-II targets, $\alpha \beta$ TCR are also now known to bind a growing list of classical and non-classical MHC molecules which cradle an extraordinary diverse array of organic and inorganic compounds (41). TCR ligands can include proteogenic peptides in HLA-E (42), lipids in the cluster of differentiation 1 (CD1) molecule $(41,43)$, vitamin metabolites in MHC-I related (MR1) molecules (44), small molecule drugs in MHC-I (45), and the empty platform of human hemochromatosis protein (HFE) (46).

Precisely mapping the complete cross-reactive profile of a therapeutic TCR candidate across the thousands of classical and non-classical MHC alleles which present a combined universe of organic and inorganic compounds is currently possible but difficult. Basic approaches are available for assessment (Table 1). For instance, scanning a group of candidate TCRs across a CPL library can quickly rule out receptors with extensive pMHC crossreactivity footprints. From these select receptors, blasting the raw CPL data across the human proteome may identify self peptides which could drive off-target activity in vivo. Candidate TCR with minimal cross-reactivity footprints as suggested by CPL scanning could then advance to in vitro testing on multi-cell subsets. Here, various cell types (monocytes, DCs, T-cells, B-cells, fibroblasts, epithelial cells, etc.) that express the HLA restriction allele of interest could be used as target cells to determine potential TCR cross-reactivity with self pMHC molecules. Target cells could be derived from primary sorted cells and/or cell lines.

\section{CONSIDERATION TWO: ALLOREACTVITY}

As mentioned above, a significant degree of degeneracy in peptide recognition likely evolved to ensure that the TCR repertoire has the capacity to recognize the enormous variety of foreign peptides that are encountered throughout life. Furthermore, broadly reactive T-cells may aid primary and memory responses where memory $\mathrm{T}$-cells for one pathogen are reactivated by a different infectious agent (47). However, limited specificity of self-MHC-restricted Tcells is also the basis of the alloresponse and its associated clinical problems.

T-cell allorecognition occurs when the immune system is presented with MHC molecules of a different allotype to that of the host. Alloreactivity becomes clinically significant in the case of solid-organ grafts or bone marrow transplants in which mismatched MHC molecules can potentially result in organ graft rejection or graft versus-host disease (GVHD). This response can be either direct, in which the T-cells mount an immune response to the foreign-pMHC, or indirect, a chronic self-MHC restricted response resulting from polymorphism in the processed antigen that can include peptides from allogeneic MHC molecules (48). It is estimated that up to $0.1-1 \%$ of T-cells are alloreactive toward a given allogeneic MHC molecule (49). However, the probability of 
Table 1 | Pre-clinical testing options for therapeutic TCR candidates.

Parameter to consider when choosing a candidate TCR for therapy

Could the candidate TCR cross-react with a peptide presented by an autologous classical and non-classical $\mathrm{MHC}$ molecule?

Could the candidate TCR alloreact with a peptide presented by a mismatched MHC molecule?

Are the germline sequences for the candidate TCR donor/patient matched?

Could the candidate TCR steer functional phenotype of recipient T-cells when used in gene therapy?

\section{Testing option/s}

Scan the candidate TCR across different primary cell subset targets (monocytes, DCs, B-cells, T-cells) sorted from prospective patients.

Scan the candidate TCR across PBMC and cell lines (monocytes, DCs, B-cells, T-cells, fibroblast, epithelial) from a library of HLA allele matched healthy donors.

Scan the candidate TCR across peptide length-matched CPL to establish a metric of crossreactivity potential.

Scan the candidate TCR across an extensive, fully HLA haplotyped cell line library. The cell line library should contain HLA alleles found at high frequency in the target population.

Compare the TRAV, TRAJ, TRBV, and TRBJ sequences of the candidate TCR with patient TR loci. Polymorphisms in these genes may alter the effectiveness of the therapeutic TCR in vivo. Additionally, if the donor/patient TR alleles do not match, or if the patient has a key TR allele deleted, there is a possibility that a patient-derived immune response could be mobilized against the "foreign" TCR.

Transduce the candidate TCR in naive T-cells in vitro or into mice with human immune system components. Prime the cultures with differing concentrations of cognate $\mathrm{Ag}$ and monitor cell fate decisions. Note temporal and final ratios in effector, memory and Tfh differentiation.

Transduce the candidate TCR in memory T-cells in vitro. Prime the cultures with differing concentrations of cognate $\mathrm{Ag}$ and monitor if cell fate is altered when compared to phenotype pre-transduction. a TCR reacting with any allogeneic MHC molecules is obviously much higher due to MHC polymorphism, and this is a potential problem for TCR therapy.

There are numerous reports of T-cell clones with dual specificity for an allo-MHC molecule and a nominal antigen complexed with self-MHC (50). The best characterized example is the response to the Epstein-Barr virus epitope FLRGRAYGL, that binds to HLA-B8, in which CTL clones were isolated that cross-reacted with one of three common alloantigens (HLAB44, B14, or B35) $(51,52)$. Interestingly, the HLA-B44 alloreactive TCR [which has also been shown to alloreact with HLA$\mathrm{B} * 5501$ (53)] is a public TCR that dominates the response to this viral epitope in most HLA-B8 ${ }^{+}$people $(54,55)$. By examining the response to this viral epitope in individuals who coexpressed HLA-B8 and one of the alloantigen targets, subdominant TCRs were identified that were not alloreactive $(55,56)$. Such TCRs would be the obvious choice for use in TCR therapy, and this approach could be used in other systems to identify non-alloreactive TCRs for therapeutic use where the dominant receptors are alloreactive.

Many other T-cell clones have been shown to cross-react with alloantigens, and work from Frans Claas's group has shown that up to $45 \%$ of virus-reactive T-cell clones from humans are alloreactive (50). Allo-HLA cross-reactivity was shown from T-cell clones raised against a range of viruses including cytomegalovirus, varicella-zoster virus, and influenza (50). These included both $\mathrm{CD}^{+}$and $\mathrm{CD}^{+}$clones alloreacting with MHC-I and MHC-II molecules, respectively, and surprisingly, they also included two distinct cytomegalovirus-reactive, MHC-I-restricted T-cell clones that recognized allogeneic MHC-II molecules (57).
The obvious way to manage the problem of T-cell alloreactivity in the context of TCR therapy is to perform preliminary in vitro screens of the TCR for cross-recognition of cell lines expressing a wide range of allo-HLA alleles. The limitation here is that it will be near impossible to screen against the huge variety of HLA molecules, given there are over 6,000 known class-I alleles and over 1,000 class-II alleles. Furthermore, alloreactive T-cells are generally also specific for one or more "self"-peptides presented by the allo-HLA molecule, and these may not be presented by cells from all tissues, or they could be derived from polymorphic gene products and are therefore not presented by all individuals or cell lines. For example, the EBV-reactive TCR described above is specific for a "self"-peptide derived from an ATP binding cassette protein ABCD3 which is presented by allo-HLA-B44 and shares only one residue with the viral peptide (58). This peptide appears to be presented at different levels in distinct tissues based on the recent observation that these T-cells recognize HLA-B44 ${ }^{+}$lymphoid cells but not epithelial and endothelial cells (59).

Although T-cell cross-reactivity with alloantigens has not proven to be a major problem in adoptive T-cell transfer clinical trials, it is an issue that should not be ignored in future trials of TCR therapy. Testing for cross-reactivity with one or more alloantigens is currently possible in vitro through target cell screening across large allo cell libraries $(50,53)$.

\section{CONSIDERATION THREE: POLYMORPHISM}

As with vaccines that elicit T-cell responses against a limited number of epitopes, TCR-based therapeutic approaches need to address the important issue of polymorphism in the genes involved in antigen presentation and those encoding for the target peptide 
antigens. Viral antigens are particularly prone to accumulating escape mutations, and so TCRs that recognize regions of viral proteins that are critical for viral fitness and are therefore highly conserved (60) should be favored for TCR therapy. Genetic instability is also a common feature of cancer cells, often resulting in the selection of antigenic variants by T-cells which allow cancer cells to escape destruction (61). The simultaneous administration of multiple TCRs that target different epitopes should circumvent these problems to some extent. Another potential mechanism through which human genetic polymorphism could create problems is if a TCR, transferred into an unrelated recipient, cross-reacts with a polymorphic self-peptide which it had not encountered during thymic negative selection, leading to damage of healthy tissue.

HLA polymorphism is also a major consideration that restricts the potential value of individual TCRs to a limited subset of any given population. As mentioned above, a huge number of HLA alleles have now been identified and therefore TCR therapy will need to be personalized to ensure recognition of epitopes presented by relevant HLA alleles. TCRs that recognize antigenic peptides that are presented by multiple HLA alleles are also valuable candidates for TCR therapy. A degree of degeneracy in HLApeptide binding has been demonstrated whereby multiple class-I alleles can share common sequence motifs due to homology of amino acids within the major pockets of the peptide binding cleft, and these groups of alleles are referred to as HLA supertypes. Based on HLA structural similarities and overlapping peptide binding motifs, nine major HLA supertypes have been proposed (62). Examples of TCRs that have the capacity to recognize individual peptides bound to multiple members of an HLA supertype have been described (63-66). These TCRs with promiscuous HLA restriction can often accommodate differences in the exposed HLA $\alpha$-helix residues between the restricting MHC and foreign MHC antigens that present the same peptide.

As with the MHC genes, allelic sequence variation is also a feature of the TCR and this issue needs to be addressed in the context of TCR therapy. Several sequencing studies have revealed considerable polymorphism within the TRAV and TRBV gene segments $(67,68)$. In one study, the TCR loci from 40 individuals across four ethnic groups were fully sequenced, and more than 550 SNPs were found, with many being situated in coding/regulatory regions of functional TCR genes and several causing null and non-functional mutations. On average, the coding region of each TCR variable gene contained two SNPs, with many more found in the $5^{\prime}, 3^{\prime}$ and intronic sequences of these segments. A total of 51 SNPs in the TRA locus and 72 SNPs in the TRB locus were found to result in amino acid changes $(67,68)$.

\section{REFERENCES}

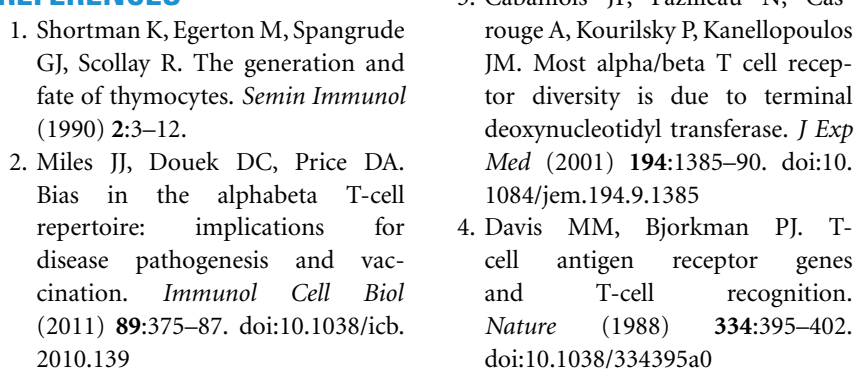

The extensive variability within the TCR gene segments raises the interesting possibility that, unless the TCR genetics are matched between donor and recipient, some TCR gene products will be seen as foreign antigens and could elicit an immune response that limits the efficacy of transferred TCRs. Particularly strong immune responses could be expected in patients with deletions or inactivating polymorphisms that prevent expression of certain TRBV genes. There are seven frequently occurring inactivating polymorphisms in functional TRBV gene segments and a large $(21.5 \mathrm{~kb})$ insertion/deletion related polymorphism in the TRB locus encompassing two $\mathrm{V}$ gene segments (67-70). In the latter case, two functional variable $\beta$ genes, TRBV6-2/TRBV6-3 and $T R B V 4-3$, are frequently deleted in all major ethnic groups (68, $70,71)$. TCRs that are encoded by V genes that include common polymorphisms could perhaps be avoided for use in TCR therapy.

\section{CONSIDERATION FOUR: FUNCTIONAL PHENOTYPE}

Recent evidence suggests that different TCRs expressed by T-cell clones of the same pMHC specificity can have different effects on immune phenotype (72). When challenged with pathogen, clonotypically distinct naive T-cells were observed to give rise to differing ratios of Th1 and Tfh progeny. These alternate differentiation programs were dependent on pMHC dwell time and/or Ag density. Interestingly, this data suggests that different TCR clonotypes of the same pMHC specificity may impart differential effects on total immune function through varying effects on macrophage activity and antibody section by B-cells. An additional complexity in this area is the observation that after priming, a single naive T-cell can have multiple fates when proceeding down the cell differentiation pathway $(73,74)$. Thus, determining exactly which differentiation program a candidate TCR induces is an important parameter when considering a receptor for therapeutic use.

\section{CONCLUDING REMARK}

The TCR is an extremely effective tool for targeting biological and non-biological molecules and vast opportunity exists to exploit these receptors therapeutically. However, TCRs are highly polymorphic by nature and intrinsically encode a considerable degree of differential functionality and cross-reactivity across a number of MHC and MHC-like molecules. These factors require that therapeutic TCR candidates are donor/patient matched and undergo the most comprehensive in vitro cross-reactivity testing we can perform with present technology. The goal of this testing should be the identification of receptor candidates with predictable cell differentiation "programs" and minimal and traceable cross-reactivity/alloreactivity footprints.

5. Lieber MR. Site-specific recombination in the immune system. FASEB $J$ (1991) 5:2934-44.

6. Arstila TP, Casrouge A, Baron V, Even J, Kanellopoulos J, Kourilsky P. A direct estimate of the human alphabeta $\mathrm{T}$ cell receptor diversity. Science (1999) 286: 958-61. doi:10.1126/science.286. 5441.958

7. Arstila TP, Casrouge A, Baron V, Even J, Kanellopoulos J, Kourilsky
P. Diversity of human alpha beta $\mathrm{T}$ cell receptors. Science (2000) 288:1135. doi:10.1126/science.288. 5469.1135a

8. Bridgeman JS, Sewell AK, Miles JJ, Price DA, Cole DK. Structural and biophysical determinants of alphabeta T-cell antigen recognition. Immunology (2012) 135:9-18. doi:10.1111/j.13652567.2011.03515.x 
9. Gras S, Burrows SR, Turner SJ, Sewell AK, McCluskey J, Rossjohn J. A structural voyage toward an understanding of the MHC-Irestricted immune response: lessons learned and much to be learned. Immunol Rev (2012) 250:61-81. doi:10.1111/j.1600-065X.2012. 01159.x

10. Rudolph MG, Stanfield RL, Wilson IA. How TCRs bind MHCs, peptides, and coreceptors. Annu Rev Immunol (2006) 24:419-66. doi:10.1146/annurev.immunol.23. 021704.115658

11. Liu YC, Miles JJ, Neller MA, Gostick E, Price DA, Purcell AW, et al. Highly divergent $\mathrm{T}$-cell receptor binding modes underlie specific recognition of a bulged viral peptide bound to a HLA class I molecule. J Biol Chem (2013) 288:15442-54. doi:10.1074/ jbc.M112.447185

12. Turner SJ, Doherty PC, McCluskey J, Rossjohn J. Structural determinants of T-cell receptor bias in immunity. Nat Rev Immunol (2006) 6:883-94. doi:10.1038/nri1977

13. Venturi V, Price DA, Douek DC, Davenport MP. The molecular basis for public T-cell responses? Nat Rev Immunol (2008) 8:231-8. doi:10. 1038/nri2260

14. Gras S, Chen Z, Miles JJ, Liu YC, Bell MJ, Sullivan LC, et al. Allelic polymorphism in the $\mathrm{T}$ cell receptor and its impact on immune responses. $J$ Exp Med (2010) 207:1555-67. doi: 10.1084/jem.20100603

15. Gras S, Saulquin X, Reiser JB, Debeaupuis E, Echasserieau K, Kissenpfennig A, et al. Structural bases for the affinity-driven selection of a public TCR against a dominant human cytomegalovirus epitope. J Immunol (2009) 183: 430-7. doi:10.4049/jimmunol. 0900556

16. Ishizuka J, Stewart-Jones GB, van der Merwe A, Bell JI, McMichael AJ, Jones EY. The structural dynamics and energetics of an immunodominant $\mathrm{T}$ cell receptor are programmed by its Vbeta domain. Immunity (2008) 28:171-82. doi:10. 1016/j.immuni.2007.12.018

17. Kjer-Nielsen L, Clements CS, Purcell AW, Brooks AG, Whisstock JC, Burrows SR, et al. A structural basis for the selection of dominant alphabeta $\mathrm{T}$ cell receptors in antiviral immunity. Immunity (2003) 18:53-64. doi:10.1016/ S1074-7613(02)00513-7

18. Stewart-Jones GB, McMichael AJ, Bell JI, Stuart DI, Jones EY. A structural basis for immunodominant human $\mathrm{T}$ cell receptor recognition.
Nat Immunol (2003) 4:657-63. doi: 10.1038/ni942

19. Tynan FE, Burrows SR, Buckle AM, Clements CS, Borg NA, Miles JJ, et al. $\mathrm{T}$ cell receptor recognition of a 'super-bulged' major histocompatibility complex class I-bound peptide. Nat Immunol (2005) 6:111422. doi:10.1038/ni1257

20. Tynan FE, Reid HH, Kjer-Nielsen L, Miles JJ, Wilce MC, Kostenko $\mathrm{L}$, et al. A $\mathrm{T}$ cell receptor flattens a bulged antigenic peptide presented by a major histocompatibility complex class I molecule. Nat Immunol (2007) 3:268-76. doi:10. 1038/ni1432

21. Koning D, Costa AI, Hoof I, Miles JJ, Nanlohy NM, Ladell K, et al. CD8+ TCR repertoire formation is guided primarily by the peptide component of the antigenic complex. J Immunol (2013) 190:931-9. doi:10.4049/jimmunol. 1202466

22. Miles JJ, Silins SL, Brooks AG, Davis JE, Misko I, Burrows SR. Tcell grit: large clonal expansions of virus-specific CD8+ T cells can dominate in the peripheral circulation for at least 18 years. Blood (2005) 106:4412-3. doi:10. 1182/blood-2005-06-2261

23. Neller MA, Burrows JM, Rist MJ, Miles JJ, Burrows SR. High frequency of herpesvirus-specific clonotypes in the human $\mathrm{T}$ cell repertoire can remain stable over decades with minimal turnover. $J$ Virol (2013) 87:697-700. doi:10. 1128/JVI.02180- 12

24. Bollard CM, Rooney CM, Heslop HE. T-cell therapy in the treatment of post-transplant lymphoproliferative disease. Nat Rev Clin Oncol (2012) 9:510-9. doi:10.1038/ nrclinonc.2012.111

25. Sellar RS, Peggs KS. Therapeutic strategies for the prevention and treatment of cytomegalovirus infection. Expert Opin Biol Ther (2012) 12:1161-72. doi:10.1517/14712598. 2012.693471

26. Park TS, Rosenberg SA, Morgan RA. Treating cancer with genetically engineered T cells. Trends Biotechnol (2011) 29:550-7. doi:10.1016/j. tibtech.2011.04.009

27. Richman SA, Healan SJ, Weber KS, Donermeyer DL, Dossett ML, Greenberg PD, et al. Development of a novel strategy for engineering high-affinity proteins by yeast display. Protein Eng Des Sel (2006) 19:255-64. doi:10.1093/ protein/gzl008

28. Li Y, Moysey R, Molloy PE, Vuidepot AL, Mahon T, Baston E, et al.
Directed evolution of human Tcell receptors with picomolar affinities by phage display. Nat Biotechnol (2005) 23:349-54. doi:10.1038/ nbt 1070

29. Dunn SM, Rizkallah PJ, Baston E, Mahon T, Cameron B, Moysey $\mathrm{R}$, et al. Directed evolution of human $\mathrm{T}$ cell receptor CDR2 residues by phage display dramatically enhances affinity for cognate peptide-MHC without increasing apparent cross-reactivity. Protein Sci (2006) 15:710-21. doi:10.1110/ps. 051936406

30. Varela-Rohena A, Molloy PE, Dunn SM, Li Y, Suhoski MM, Carroll RG, et al. Control of HIV-1 immune escape by CD8 $\mathrm{T}$ cells expressing enhanced T-cell receptor. Nat Med (2008) 14:1390-5. doi:10.1038/nm. 1779

31. Liddy N, Bossi G, Adams KJ, Lissina A, Mahon TM, Hassan NJ, et al. Monoclonal TCR-redirected tumor cell killing. Nat Med (2012) 18:980 7. doi:10.1038/nm.2764

32. Mason D. A very high level of crossreactivity is an essential feature of the T-cell receptor. Immunol Today (1998) 19:395-404. doi:10. 1016/S0167-5699(98)01299-7

33. Sewell AK. Why must $\mathrm{T}$ cells be cross-reactive? Nat Rev Immunol (2012) 12:669-77. doi:10.1038/nri3279

34. Wooldridge L, Ekeruche-Makinde J, van den Berg HA, Skowera A, Miles JJ, Tan MP, et al. A single autoimmune $\mathrm{T}$ cell receptor recognizes more than a million different peptides. J Biol Chem (2012) 287:116877. doi:10.1074/jbc.M111.289488

35. Ekeruche-Makinde J, Miles JJ, van den Berg HA, Skowera A, Cole DK, Dolton G, et al. Peptide length determines the outcome of TCR/peptide-MHCI engagement. Blood (2013) 121:1112-23. doi:10. 1182/blood-2012-06-437202

36. Morgan RA, Chinnasamy N, AbateDaga D, Gros A, Robbins PF, Zheng $Z$, et al. Cancer regression and neurological toxicity following antiMAGE-A3 TCR gene therapy. J Immunother (2013) 36:133-51. doi: 10.1097/CJI.0b013e3182829903

37. Mohammed F, Cobbold M, Zarling AL, Salim M, BarrettWilt GA, Shabanowitz J, et al. Phosphorylation-dependent interaction between antigenic peptides and MHC class I: a molecular basis for the presentation of transformed self. Nat Immunol (2008) 9:1236-43. doi:10.1038/ni.1660

38. Dowling W, Thompson E, Badger C, Mellquist JL, Garrison AR,
Smith JM, et al. Influences of glycosylation on antigenicity, immunogenicity, and protective efficacy of ebola virus GP DNA vaccines. J Virol (2007) 81:1821-37. doi:10. 1128/JVI.02098-06

39. Hill JA, Bell DA, Brintnell W, Yue D, Wehrli B, Jevnikar AM, et al. Arthritis induced by posttranslationally modified (citrullinated) fibrinogen in DR4-IE transgenic mice. J Exp Med (2008) 205:967-79. doi: 10.1084/jem.20072051

40. Chen W, Yewdell JW, Levine RL, Bennink JR. Modification of cysteine residues in vitro and in vivo affects the immunogenicity and antigenicity of major histocompatibility complex class Irestricted viral determinants. J Exp Med (1999) 189:1757-64. doi:10. 1084/jem.189.11.1757

41. Adams EJ, Luoma AM. The adaptable major histocompatibility complex (MHC) fold: structure and function of nonclassical and MHC class I-like molecules. Annu Rev Immunol (2013) 31:529-61. doi:10.1146/annurev-immunol032712-095912

42. Sullivan LC, Hoare HL, McCluskey J, Rossjohn J, Brooks AG. A structural perspective on MHC class $\mathrm{Ib}$ molecules in adaptive immunity. Trends Immunol (2006) 27:413-20. doi:10.1016/j.it.2006.07.006

43. Rossjohn J, Pellicci DG, Patel O, Gapin L, Godfrey DI. Recognition of CD1d-restricted antigens by natural killer T cells. Nat Rev Immunol (2012) 12:845-57. doi:10. 1038/nri3328

44. Kjer-Nielsen L, Patel O, Corbett AJ, Le Nours J, Meehan B, Liu L, et al. MR1 presents microbial vitamin B metabolites to MAIT cells. Nature (2012) 491:717-23. doi:10. 1038/nature11605

45. Illing PT, Vivian JP, Dudek NL, Kostenko L, Chen Z, Bharadwaj $M$, et al. Immune selfreactivity triggered by drugmodified HLA-peptide repertoire. Nature (2012) 486:554-8. doi:10.1038/nature11147

46. Rohrlich PS, Fazilleau N, Ginhoux F, Firat H, Michel F, Cochet $\mathrm{M}$, et al. Direct recognition by alphabeta cytolytic $\mathrm{T}$ cells of Hfe, a MHC class Ib molecule without antigen-presenting function. Proc Natl Acad Sci U S A (2005) 102:12855-60. doi:10.1073/ pnas.0502309102

47. Welsh RM, Che JW, Brehm MA, Selin LK. Heterologous immunity between viruses. Immunol Rev (2010) 235:244-66. 
48. Ely LK, Burrows SR, Purcell AW, Rossjohn J, McCluskey J. T-cells behaving badly: structural insights into alloreactivity and autoimmunity. Curr Opin Immunol (2008) 20:575-80. doi:10.1016/j.coi.2008. 07.006

49. Suchin EJ, Langmuir PB, Palmer E, Sayegh MH, Wells AD, Turka LA. Quantifying the frequency of alloreactive T cells in vivo: new answers to an old question. J Immunol (2001) 166:973-81.

50. Amir AL, D’Orsogna LJ, Roelen DL, van Loenen MM, Hagedoorn $\mathrm{RS}$, de Boer R, et al. Allo-HLA reactivity of virus-specific memory $\mathrm{T}$ cells is common. Blood (2010) 115:3146-57. doi:10.1182/ blood-2009-07-234906

51. Burrows SR, Khanna R, Burrows JM, Moss DJ. An alloresponse in humans is dominated by cytotoxic T lymphocytes (CTL) crossreactive with a single Epstein-Barr virus CTL epitope: implications for graft-versus-host disease. J Exp Med (1994) 179:1155-61. doi:10.1084/ jem.179.4.1155

52. Burrows SR, Silins SL, Khanna R, Burrows JM, Rischmueller M, McCluskey J, et al. Cross-reactive memory $\mathrm{T}$ cells for Epstein-Barr virus augment the alloresponse to common human leukocyte antigens: degenerate recognition of major histocompatibility complexbound peptide by $\mathrm{T}$ cells and its role in alloreactivity. Eur J Immunol (1997) 27:1726-36. doi:10.1002/eji. 1830270720

53. D’Orsogna LJ, Amir AL, Zoet YM, van der Meer-Prins PM, van der Slik AR, Kester MG, et al. New tools to monitor the impact of viral infection on the alloreactive T-cell repertoire. Tissue Antigens (2009) 74:290-7. doi:10.1111/j.1399-0039. 2009.01311.x

54. Argaet VP, Schmidt CW, Burrows SR, Silins SL, Kurilla MG, Doolan $\mathrm{DL}$, et al. Dominant selection of an invariant $\mathrm{T}$ cell antigen receptor in response to persistent infection by Epstein-Barr virus. J Exp Med (1994) 180:2335-40. doi:10.1084/ jem.180.6.2335

55. Burrows SR, Silins SL, Moss DJ, Khanna R, Misko IS, Argaet VP. T cell receptor repertoire for a viral epitope in humans is diversified by tolerance to a background major histocompatibility complex antigen. J Exp Med (1995) 182: 1703-15. doi:10.1084/jem.182.6. 1703

56. Gras S, Burrows SR, Kjer-Nielsen L, Clements CS, Liu YC, Sullivan LC, et al. The shaping of $\mathrm{T}$ cell receptor recognition by self-tolerance. Immunity (2009) 30:193-203. doi: 10.1016/j.immuni.2008.11.011

57. Rist M, Smith C, Bell MJ, Burrows SR, Khanna R. Cross-recognition of HLA DR4 alloantigen by virusspecific CD8+ T cells: a new paradigm for self-/nonself-recognition. Blood (2009) 114:2244-53. doi:10. 1182/blood-2009-05-222596

58. Macdonald WA, Chen Z, Gras S, Archbold JK, Tynan FE, Clements $\mathrm{CS}$, et al. $\mathrm{T}$ cell allorecognition via molecular mimicry. Immunity (2009) 31:897-908. doi:10.1016/j. immuni.2009.09.025

59. D’Orsogna LJ, Roelen DL, van der Meer-Prins EM, van der Pol P, Franke-van Dijk ME, Eikmans $M$, et al. Tissue specificity of cross-reactive allogeneic responses by EBV EBNA3A-specific memory $\mathrm{T}$ cells. Transplantation (2011) 91:494-500. doi:10.1097/TP. 0b013e318207944c

60. Peut V, Kent SJ. Fitness constraints on immune escape from HIV: implications of envelope as a target for both HIV-specific $\mathrm{T}$ cells and antibody. Curr HIV Res (2006) 4:191-7. doi:10.2174/ 157016206776055110

61. Liu JQ, Bai XF. Overcoming immune evasion in $\mathrm{T}$ cell therapy of cancer: lessons from animal models. Curr Mol Med (2008) 8:68-75. doi:10.2174/156652408783565531

62. Sette A, Sidney J. Nine major HLA class I supertypes account for the vast preponderance of HLA-A and -B polymorphism. Immunogenetics (1999) 50:201-12. doi:10.1007/ s002510050594

63. Burrows SR, Elkington RA, Miles JJ, Green KJ, Walker S, Haryana SM, et al. Promiscuous CTL recognition of viral epitopes on multiple human leukocyte antigens: biological validation of the proposed HLA A24 supertype. J Immunol (2003) 171:1407-12.
64. Fleischhauer K, Tanzarella S, Wallny HJ, Bordignon C, Traversari C. Multiple HLA-A alleles can present an immunodominant peptide of the human melanoma antigen Melan-A/MART-1 to a peptidespecific HLA-A ${ }^{\star} 0201+$ cytotoxic T cell line. J Immunol (1996) 157:78797.

65. Khanna R, Burrows SR, Nicholls J, Poulsen LM. Identification of cytotoxic $\mathrm{T}$ cell epitopes within Epstein-Barr virus (EBV) oncogene latent membrane protein 1 (LMP1): evidence for HLA A2 supertype-restricted immune recognition of EBV-infected cells by LMP1-specific cytotoxic T lymphocytes. Eur J Immunol (1998) 28:451-8. doi:10.1002/(SICI)15214141(199802)28:02<451::AIDIMMU451>3.3.CO;2-L

66. Threlkeld SC, Wentworth PA, Kalams SA, Wilkes BM, Ruhl DJ, Keogh E, et al. Degenerate and promiscuous recognition by CTL of peptides presented by the MHC class I A3-like superfamily: implications for vaccine development. J Immunol (1997) 159:1648-57.

67. Mackelprang R, Livingston RJ, Eberle MA, Carlson CS, Yi Q, Akey $\mathrm{JM}$, et al. Sequence diversity, natural selection and linkage disequilibrium in the human $\mathrm{T}$ cell receptor alpha/delta locus. Hum Genet (2006) 119:255-66. doi:10. 1007/s00439-005-0111-z

68. Subrahmanyan L, Eberle MA, Clark AG, Kruglyak L, Nickerson DA. Sequence variation and linkage disequilibrium in the human T-cell receptor beta (TCRB) locus. Am J Hum Genet (2001) 69:381-95. doi: $10.1086 / 321297$

69. Mackelprang R, Carlson CS, Subrahmanyan L, Livingston RJ, Eberle MA, Nickerson DA. Sequence variation in the human T-cell receptor loci. Immunol Rev (2002) 190:2639. doi:10.1034/j.1600-065X.2002. 19003.x

70. Seboun E, Robinson MA, Kindt TJ, Hauser SL. Insertion/deletionrelated polymorphisms in the human $\mathrm{T}$ cell receptor beta gene complex. J Exp Med (1989) 170:1263-70. doi:10.1084/jem.170.4.1263
71. Zhao TM, Whitaker SE, Robinson MA. A genetically determined insertion/deletion related polymorphism in human $\mathrm{T}$ cell receptor beta chain (TCRB) includes functional variable gene segments. J Exp Med (1994) 180:1405-14. doi:10. 1084/jem.180.4.1405

72. Tubo NJ, Pagan AJ, Taylor JJ, Nelson RW, Linehan JL, Ertelt JM, et al. Single naive CD4+ T cells from a diverse repertoire produce different effector cell types during infection. Cell (2013) 153:785-96. doi: 10.1016/j.cell.2013.04.007

73. Gerlach C, van Heijst JW, Swart E, Sie D, Armstrong N, Kerkhoven RM, et al. One naive $\mathrm{T}$ cell, multiple fates in CD8+ T cell differentiation. J Exp Med (2010) 207:1235-46. doi:10.1084/jem. 20091175

74. Stemberger C, Huster KM, Koffler M, Anderl F, Schiemann M, Wagner $\mathrm{H}$, et al. A single naive CD8+ $\mathrm{T}$ cell precursor can develop into diverse effector and memory subsets. Immunity (2007) 27:985-97. doi:10.1016/j.immuni.2007.10.012

Conflict of Interest Statement: The authors declare that the research was conducted in the absence of any commercial or financial relationships that could be construed as a potential conflict of interest.

Received: 11 May 2013; accepted: 22 July 2013; published online: 05 August 2013. Citation: Burrows $S R$ and Miles JJ (2013) Immune parameters to consider when choosing $T$-cell receptors for therapy. Front. Immunol. 4:229. doi: 10.3389/fimmu.2013.00229

This article was submitted to Frontiers in $T$ Cell Biology, a specialty of Frontiers in Immunology.

Copyright (c) 2013 Burrows and Miles. This is an open-access article distributed under the terms of the Creative Commons Attribution License (CC BY). The use, distribution or reproduction in other forums is permitted, provided the original author(s) or licensor are credited and that the original publication in this journal is cited, in accordance with accepted academic practice. No use, distribution or reproduction is permitted which does not comply with these terms. 